Proc. Estonian Acad. Sci. Biol. Ecol., 2002, 51, 3, 147-162

\title{
Shape and area of simple narrow leaves
}

\author{
Matti Mõttus*, Juhan Ross, and Vello Ross \\ Tartu Observatory, 61602 Tõravere, Tartumaa, Estonia \\ Received 12 February 2002, in revised form 8 May 2002

\begin{abstract}
New comprehensive models of radiative transfer in plant canopies require detailed information about 3D architecture at the stand and plant levels. In such models, the leaf (or shoot for conifers) has been accepted as the smallest structural unit. Because of the great variability of leaf shape and area of different plant species, different methods have been elaborated for the description of this unit. In this paper, an analytical leaf shape function is proposed for flat narrow leaves. The leaf shape function yields the half-width of the leaf at point $x$ if the midrib of the leaf coincides with the $x$-axis using three parameters: leaf length, maximum leaf width, and a leaf shape parameter. Integration over the $x$-coordinate of the shape function from the leaf insertion point to the leaf tip yields the area of the leaf.

For the application of the model, measurements of the leaf parameters of two willow species, Salix viminalis and S. dasyclados, were used. The measurements were carried out in 1996-2001 at Tartu Observatory, Estonia. Statistical analysis of the variability of leaf length, maximum leaf width, and leaf area revealed very large variations of these parameters. For example, leaf area varies between 10 and $2700 \mathrm{~mm}^{2}$ for $S$. viminalis and between 6 and $7000 \mathrm{~mm}^{2}$ for $S$. dasyclados. Despite the great variability of leaf parameters, the proposed formulas for leaf area and leaf shape follow closely the actual shape of the leaf. Agreement is somewhat better for S. dasyclados than for S. viminalis.
\end{abstract}

Key words: plant architecture, leaf area, leaf shape, willow leaves.

\section{INTRODUCTION}

In new radiative transfer models of discontinuous plant canopies (Myneni et al., 1986a, b; Ross \& Marshak, 1988; Knyazikhin et al., 1992; Govaerts, 1996; Shabanov et al., 2000), canopy is an area with plants distributed statistically. Plants having a 3D geometry consist of stems, branches, shoots, and leaves of a particular shape.

\footnotetext{
*Corresponding author: mottus@aai.ee
} 
For the description of the 3D plant geometry, various novel methods have been elaborated (reviewed partly by Moulia \& Sinoquet, 1993): silhouette method (Bonhomme \& Varlet-Grancher, 1978; Prevot \& Brunet, 1993), stereovision (Ivanov et al., 1995; Andrieu et al., 1995), laser-beam telemetric systems (Vanderbilt et al., 1979; Sinoquet et al., 1993; Tanaka et al., 1998), magnetic digitizers (Moulia \& Sinoquet, 1993; Sinoquet \& Rivet, 1997; Sinoquet et al., 1998), sonic digitizers (Shibayama et al., 1985), lidar or X-ray computer tomography (Vanderbilt \& Kilgore, 1981; Vanderbilt, 1985), and Lindenmayer L-systems and fractal models (Chen et al., 1994; Fournier \& Andrieu, 1998; Lewis, 1999).

In modelling crown shape, axisymmetrical envelopes (cylinders, cones, spheroids, ellipsoids, etc.) have been commonly used. Asymmetrical crown shape models were developed by Cescatti (1997).

The above referred methods are able to provide detailed information about the plants' 3D geometry, but they are technically complicated and time consuming and their application in field measurements is difficult.

In botany and plant ecology, the problem of estimation of the shape and area of individual leaves has been noted for a long time (e.g. reviews of Kvet \& Marshall, 1971; Ross, 1981; Sinoquet \& Andrieu, 1993). For deciduous plants, the leaf is considered the smallest geometrical plant unit, while its counterpart for coniferous trees is the shoot (e.g., Kellomäki \& Oker-Blom, 1983; Stenberg et al., 1993; Nilson \& Ross, 1997).

Usually, in modelling leaf shape and area, simple geometrical figures such as a circular disk, an ellipse, a double triangle, etc. are used. Some of these simple shapes are drawn in the $x y$ coordinate system in Fig. 1.
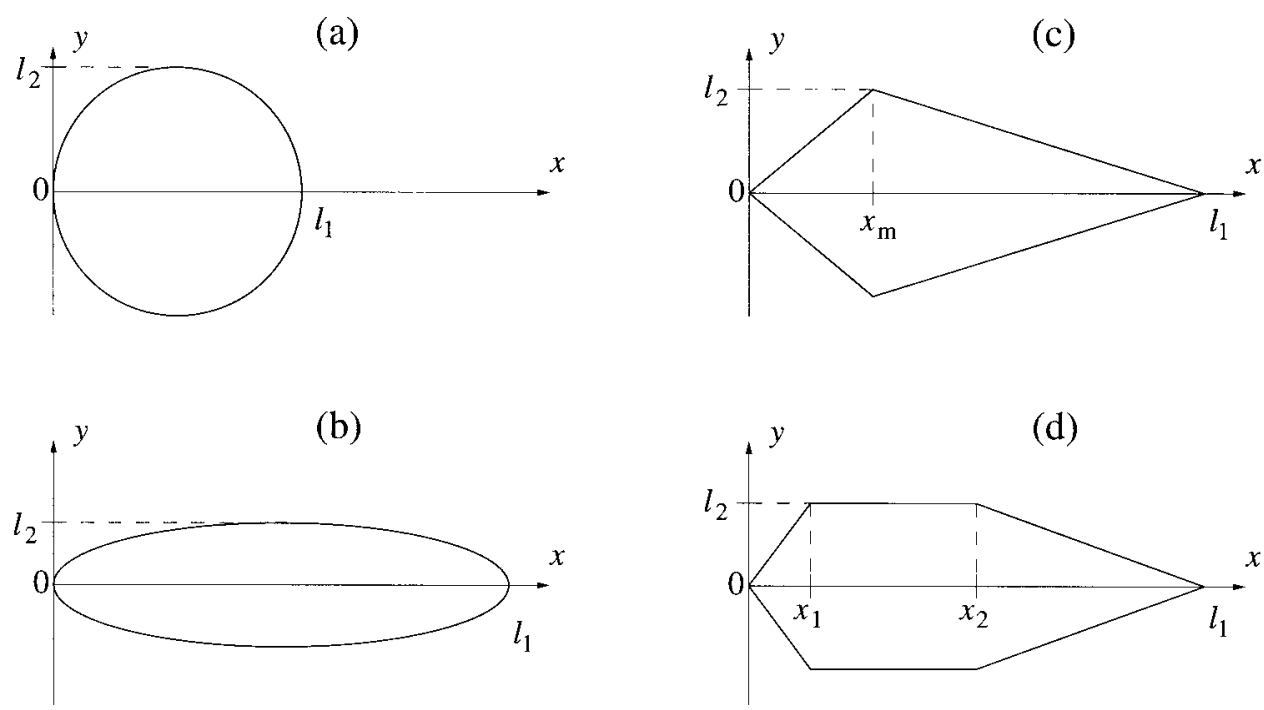

Fig. 1. Simple leaf models: a, round disc; b, ellipse; c, double triangle; and d, double trapezoid. 
When leaf shape is intricate or cannot be modelled with sufficient accuracy using a simple geometrical figure, leaf area is expressed by the formula (e.g., Kvet \& Marshall, 1971; Ross, 1981):

$$
S_{\mathrm{L}}=K_{\mathrm{L}} l_{1} l_{2}
$$

where $K_{\mathrm{L}}$ is the leaf form-factor, and $l_{1}$ and $l_{2}$ are the leaf length and width, respectively. For many species, $K_{\mathrm{L}}$ varies between 0.61 and 0.81 (Sinoquet \& Andrieu, 1993). The form-factors, formulas for leaf area, and shape functions of the geometrical figures in Fig. 1 are given in Table 1. The disadvantage of using simple geometrical figures is that the actual value of the form-factor need not coincide with that of the geometrical figure. Given the area of a leaf, simple geometrical figures also need not estimate correctly some other characteristic features of the leaf (its length, maximum width, or the distribution of leaf area along the $x$-axis).

The problem of estimation of the shape and area of a leaf is complicated for compound or nonflat (tortuous, bent, and undulated) leaves. An estimation of the area of nonflat leaves is reported by Chen \& Black (1992).

In many papers, the real maize leaf has been investigated as a 3D object, e.g. in Sinoquet et al. (1991), Aries et al. (1993), España et al. $(1998,1999)$, and Fournier \& Anrieu (1998). Most commonly, the maize leaf was measured and modelled as a set of triangles in 3D-space. For maize, sugar cane, and wheat leaves, Bonhomme \& Varlet-Grancher (1978) proposed a second-order polynomial

Table 1. Shape function $f_{\mathrm{L}}$, leaf area $S_{\mathrm{L}}$, and form-factor $K_{\mathrm{L}}$ for some simple leaf models in Fig. 1

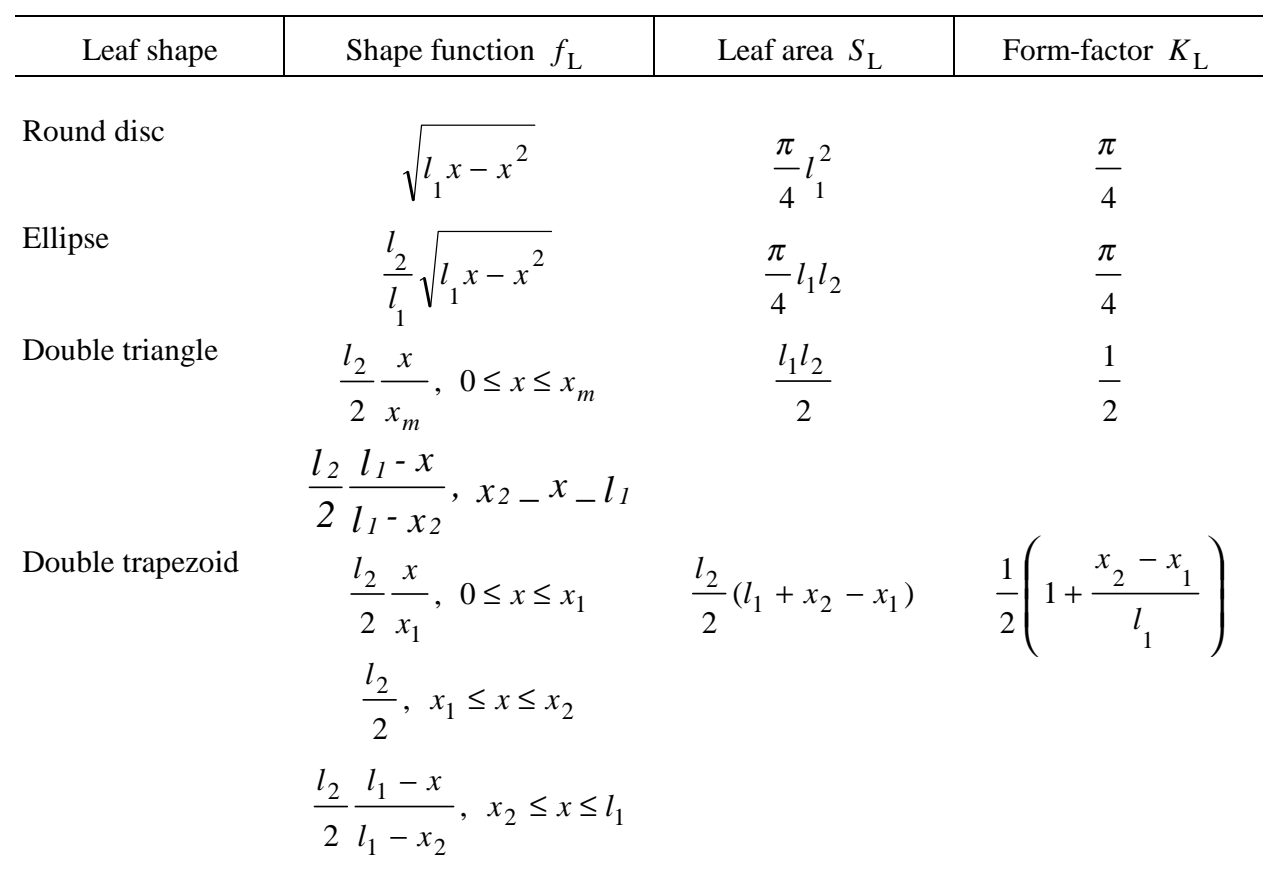




$$
\frac{y}{l_{2}}=a+b\left(\frac{x}{l_{1}}\right)+c\left(\frac{x}{l_{1}}\right)^{2},
$$

i.e. a 5-parameter function. Later, several other authors have proposed polynomials of fourth or fifth degree to describe the shape of a maize leaf, e.g. Sinoquet \& Bonhomme (1989), Prevot \& Brunet (1993), Ivanov et al. (1995), Fournier \& Andrieu (1998).

Ustin et al. (1991) studied the leaf geometry of walnut trees. These leaves are odd-pinnately compound with five, seven, or nine leaflets, producing nonrandom clusters of laminae.

For application in radiation transfer models, the description of the shape of a modelled leaf should not only follow closely the measured leaf shape, but also it has to be quite robust. As it is impossible and unproductive to measure the shapes of leaves of plants forming the natural vegetation cover, a reliable method must be devised for the simulation of the variation of natural leaf contour based on a small number of parameters describing the plants.

The aim of this paper is to propose an analytical shape function $f_{\mathrm{L}}(x)$ for a narrow simple leaf whose shape cannot be modelled by simple geometrical figures. This formula gives the leaf shape function $f_{\mathrm{L}}(x)$ and the leaf area $S_{\mathrm{L}}$ using only three linear leaf parameters: the leaf length $l_{1}$, the maximum leaf width $l_{2}$, and the shape parameter $\beta$, which is a function of the form-factor $K_{\mathrm{L}}$. The formula and the influence of its parameters will be analysed. Next, the formula will be fitted to real leaves using measurement data for willow (Salix viminalis and S. dasyclados) leaves.

\section{MATERIALS AND METHODS}

Consider the shape and area of a flat leaf whose midrib is a straight line directed along the $x$-axis in the $x y$-coordinate system. The origin of the coordinate system is located at the leaf's insertion point. Let leaf half-width at point $x$ on the midrib be $y$, which we will describe using the leaf shape function $y=f_{\mathrm{L}}(x)$. Coordinate $x$ varies between 0 and $l_{1}$, and coordinate $y$ varies between 0 and $l_{2} / 2$, where $l_{1}$ is leaf length and $l_{2}$ is maximum leaf width at some point $x=x_{m}$. We will suppose that the upper and lower halves of leaf shape are similar relative to leaf midrib ( $x$-axis), so that the function $f_{\mathrm{L}}(x)$ expresses the leaf shape of the upper half and $-f_{\mathrm{L}}(x)$ expresses the leaf shape of the lower half.

The leaf shape function $f_{\mathrm{L}}(x)$ must fulfil the conditions

and

$$
f_{\mathrm{L}}(0)=f_{\mathrm{L}}\left(l_{1}\right)=0
$$

$$
\left.2 f_{\mathrm{L}}(x)\right|_{x=x_{m}}=l_{2} .
$$


When leaf contour is smooth, the additional condition

$$
\left.\frac{\mathrm{d} f_{\mathrm{L}}(x)}{\mathrm{d} x}\right|_{x=x_{m}}=0
$$

is imposed on $f_{\mathrm{L}}(x)$.

The leaf area $S_{\mathrm{L}}$ is determined by the integral

$$
S_{\mathrm{L}}=2 \int_{0}^{l_{1}} f_{\mathrm{L}}(x) \mathrm{d} x .
$$

Besides satisfying the conditions (3) to (5), a leaf shape function must approximate the contour of the real leaf and allow for a realistic form-factor, i.e. the area calculated using Eq. (6) must equal the measured area. Besides different plant species having leaves with different form-factors, a considerable amount of variation is introduced even in leaves picked from the same plant. Thus, a shape function has to depend on some parameters describing within-species or between-species variability. The number of parameters can be arbitrarily large, depending on the accuracy of fit required by the modeller. The division of leaves into triangles results in a huge number of parameters, polynomials require four or five independent parameters. As all formulas are approximations chosen as the best fit to a selected subset of leaves, they cannot describe the full variation of leaves (e.g. damage caused by pests). For simplicity, the number of parameters should thus be kept as low as possible without losing the essential variation; also, a range or a distribution should be provided for each parameter.

Some species (cereals, willow, eucalyptus, reed, etc.) have long narrow leaves with a smooth shape, but for reasons described above their shape is difficult to model by simple functions. For such leaves we propose the following threeparametric shape function

$$
f_{\mathrm{L}}\left(x, \beta, l_{1}, l_{2}\right)=\frac{l_{2}}{2}\left(1-\beta \frac{x}{l_{1}}\right)\left(\frac{x}{l_{1}}-\left(\frac{x}{l_{1}}\right)^{2}\right)^{\beta} v(\beta),
$$

where the parameter $\beta(0 \leq \beta \leq 1)$ characterizes leaf shape and $v(\beta)$ is a characteristic function.

As shown later, the single additional parameter $\beta$ depends only on the form-factor $K_{\mathrm{L}}$. This makes its interpretation easy and gives the possibility of estimating leaf shape function from measurements of leaf length, leaf width, and leaf area only, while preserving the natural variability of leaf shape. The cost of keeping the number of additional parameters at the lowest possible value is increased mathematical complexity, e.g. compared with polynomials. However, this need not be a disadvantage, as mathematical results have to be obtained only once for the whole range of $\beta$, while models with several parameters may require additional computations for each different set of parameters.

The first derivative of the shape function $f_{\mathrm{L}}(x)$ is

$$
\frac{\mathrm{d} f_{\mathrm{L}}}{\mathrm{d} x}=\frac{l_{2}}{2 l_{1}} \beta v(\beta)\left(\frac{x}{l_{1}}\right)^{\beta-1}\left(1-\frac{x}{l_{1}}\right)^{\beta-1}\left[1-\frac{x}{l_{1}}(\beta+3)+(2 \beta+1)\left(\frac{x}{l_{1}}\right)^{2}\right] .
$$


From (8) follows that

$$
\lim _{x \rightarrow 0} \frac{\mathrm{d} f_{\mathrm{L}}}{\mathrm{d} x}=\lim _{x \rightarrow l_{1}} \frac{\mathrm{d} f_{\mathrm{L}}}{\mathrm{d} x}=\infty .
$$

It means that at the leaf tip points $x=0$ and $x=l_{1}$, the shape function crosses the $x$-axis perpendicularly.

Integrating $f_{\mathrm{L}}(x)$ in accordance with Eq. (6), we obtain for leaf area

$$
S_{\mathrm{L}}\left(\beta, l_{1}, l_{2}\right)=l_{1} l_{2} v(\beta)[B(1+\beta, 1+\beta)-\beta B(2+\beta, 1+\beta)],
$$

where $B(p, q)=\int_{0}^{1} u^{p-1}(1-u)^{q-1} \mathrm{~d} u$ is the beta-function.

From Eqs. (5) and (8) we find that

$$
x_{m}(\beta)=l_{1} \frac{3+\beta-u(\beta)}{2(1+2 \beta)},
$$

where $u(\beta)=\sqrt{5-2 \beta+\beta^{2}}$.

The function $x_{m} / l_{1}$ is graphically expressed in Fig. 2a. The dependence of $x_{m} / l_{1}$ on $\beta$ is quasilinear and, with $\beta$ changing from 0 to $1, x_{m} / l_{1}$ changes only slightly, from 0.38 to 0.335 .

Inserting $x_{m}$ from Eq. (11) into (7), we obtain

$$
f_{\mathrm{L}}\left(x_{m}\right)=\frac{l_{2}}{2} v(\beta) \frac{\left(2+\beta-\beta^{2}+\beta u(\beta)\right)\left(\beta^{2}+5 \beta-4+(2-\beta) u(\beta)\right)^{\beta}}{2^{1+\beta}(1+2 \beta)} .
$$
have

Taking into account Eqs. (4) and (12), for the characteristic function $v(\beta)$ we

$$
v(\beta)=\frac{2^{1+\beta}(1+2 \beta)^{1+2 \beta}}{\left(2+\beta-\beta^{2}+\beta u(\beta)\right)\left(\beta^{2}+5 \beta-4+(1-\beta) u(\beta)\right)^{\beta}} .
$$

Equation (13) shows that the function $v(\beta)$ depends only on the leaf shape parameter $\beta$.

Figure $2 \mathrm{~b}$ expresses $v(\beta)$ as a function of $\beta$. Comparison of Eq. (1) and Eq. (10) yields the theoretical equation for the leaf form-factor $K_{\mathrm{L}}$,

$$
K_{\mathrm{L}}(\beta)=v(\beta)[B(1+\beta, 1+\beta)-\beta B(2+\beta, 1+\beta)] .
$$

Equation (14) shows that in our leaf model, the leaf form-factor $K_{\mathrm{L}}$ is a function of the leaf shape parameter $\beta$ only. 

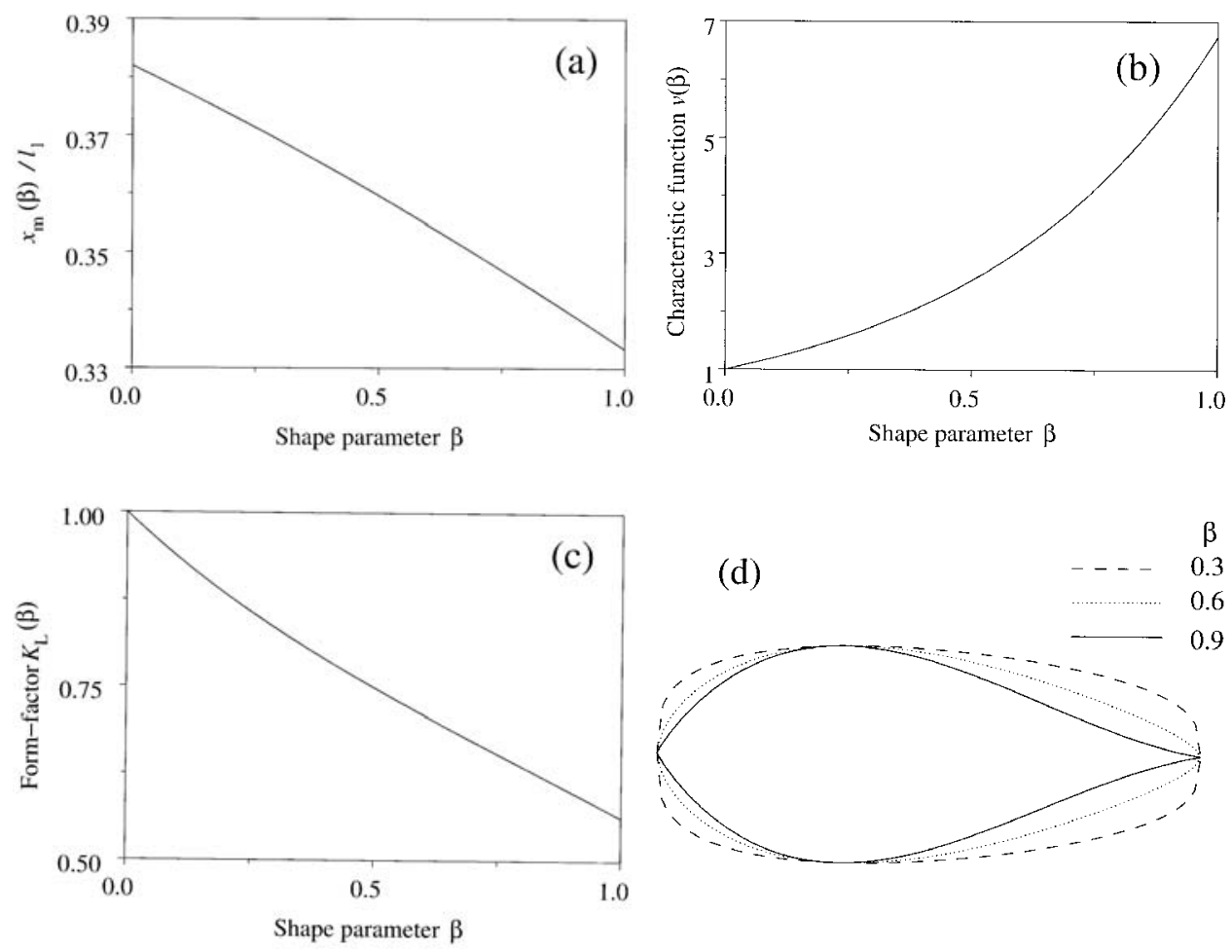

Fig. 2. Different leaf characteristics as functions of the leaf shape parameter $\beta$ : a, $x_{m}(\beta) / l_{1}$ relative distance of the maximum leaf width $l_{2}$ along the midrib; b, $v(\beta)$ - characteristic function; c, $K_{\mathrm{L}}(\beta)$ - leaf form-factor; d, the leaf shape function $f_{\mathrm{L}}(x)$ at different values of the leaf shape parameter $\beta$ ( $l_{1}$ and $l_{2}$ are constant).

Figure $2 \mathrm{c}$ shows that with increasing $\beta$, the form-factor $K_{\mathrm{L}}$ decreases quasilinearly. Figure $2 \mathrm{~d}$ illustrates the leaf shape function at different values of the leaf shape parameter $\beta$ with constant $l_{1}$ and $l_{2}$.

In the definition of $f_{\mathrm{L}}\left(x, \beta, l_{1}, l_{2}\right)$ we assumed that $0 \leq \beta \leq 1$. Different leaf characteristics at the limiting values $\beta=0$ and $\beta=1$ are given in Table 2 . At $\beta=0$, the shape function $f_{\mathrm{L}}$ is transformed to a quadrangle with length $l_{1}$, width $l_{2} / 2$, and area $S_{\mathrm{L}}=l_{1} l_{2}$. At $\beta=1$, the shape function $f_{\mathrm{L}}$ is a third-order polynomial, $\left.f_{\mathrm{L}}(x)\right|_{\max }=f_{\mathrm{L}}\left(\frac{l_{1}}{3}\right)$, the form-factor $K_{\mathrm{L}}$ equals $9 / 16$ and the leaf area $S_{\mathrm{L}}=\frac{9}{16} l_{1} l_{2}$. 
Table 2. Leaf characteristics at the limiting values of the shape factor: $\beta=0$ and $\beta=1$

\begin{tabular}{c|c|c|c|c|c}
\hline$\beta$ & $f_{\mathrm{L}}(x)$ & $x_{m}$ & $v(\beta)$ & $K_{\mathrm{L}}$ & $S_{\mathrm{L}}$ \\
\hline 0 & $\frac{l_{2}}{2}$ & - & 1 & 1 & $l_{1} l_{2}$ \\
1 & $\frac{27}{8} \frac{l_{2}}{l_{1}} x\left(1-\frac{x}{l_{2}}\right)^{2}$ & $\frac{l_{1}}{3}$ & $\frac{24}{7}$ & $\frac{9}{16}$ & $\frac{9}{16} l_{1} l_{2}$
\end{tabular}

To apply the leaf shape function (Eq. (7)) for estimating the shape and area of a leaf, the form-factor $K_{\mathrm{L}}$ must be considered a species-specific constant. To calculate $K_{\mathrm{L}}$ and initialize the model, the following steps must be followed:

(1) measurement of $l_{1}, l_{2}$, and leaf area $S_{\mathrm{L}}$ of different model leaves whose number must be statistically sufficient;

(2) calculation of the leaf form-factor $K_{\mathrm{L}}$ using Eq. (1);

(3) study of the statistical distribution of $K_{\mathrm{L}}$ and estimation of the mean value $\bar{K}_{\mathrm{L}}$ as a species-specific parameter;

(4) application of Eqs. (13) and (14) for calculating the mean value $\bar{\beta}$ as a species-specific parameter, as well as the function $v(\bar{\beta})$.

After calibration of the model, the following procedure should be used:

(1) measurement of the values of $l_{1}$ and $l_{2}$, and calculation of leaf area in accordance with Eq. (1) with the use of the species-specific value of the leaf formfactor $\bar{K}_{\mathrm{L}}$;

(2) calculating of the leaf shape function $f_{\mathrm{L}}(x)$ in accordance with Eq. (7) with the use of the species-specific parameters $\bar{\beta}$ and $v(\bar{\beta})$.

To simplify step 4 of model calibration, $\beta$ can be considered a linear function of $K_{\mathrm{L}}$. Although the relationship between $K_{\mathrm{L}}$ and $\beta$ is quasilinear in the whole range of $\beta$ (Fig. 2c), a local approximation can be used. This can reduce the time of repetitive calculations of $\beta$.

We used the leaves of two willow species, S. viminalis and S. dasyclados, to fit the leaf shape function $f_{\mathrm{L}}$ (Eq. (7)) and the leaf area $S_{\mathrm{L}}$ (Eqs. (1) and (6)) to the measured data. During 1996-2001, leaves were taken from fast growing willow plantations at Tartu Observatory, Estonia. A more detailed description of this plantation is given in Ross \& Ross $(1996,1998)$. The leaves were collected from different heights of plants in midsummer.

The leaf length $l_{1}$, the maximum leaf width $l_{2}$, and the area $S_{\mathrm{L}}$ were measured with a CI-203 Area Meter, CID, Inc.

For each of the measured parameters, $l_{1}, l_{2}$, and $S_{\mathrm{L}}$, probability density histograms were calculated. Data for $S$. viminalis have been published earlier by Ross \& Ross (1998), and a short description of the data for S. dasyclados will be given below in this paper.

In total, about $3000 \mathrm{~S}$. viminalis and $1500 \mathrm{~S}$. dasyclados leaves were measured. Two-thirds of the leaves were used to estimate the species-specific parameters $\bar{\beta}$ 
and $\bar{K}_{\mathrm{L}}$. One-third was used for testing the method: leaf area was calculated using Eq. (1) and compared with the leaf area measured with the area meter.

\section{RESULTS AND DISCUSSION}

To describe the variability of the measured leaf parameters for both species, the probability distribution of the leaf length $l_{1}$, the maximum leaf width $l_{2}$, and the leaf area $S_{\mathrm{L}}$ were calculated and fitted by lognormal distributions.

The results of the fitting and some statistical parameters are given in Table 3. It is evident that variation in the size of a willow leaf is quite large. For S. viminalis, the maximum leaf area exceeds the minimum area about 270 times, for S. dasyclados over 100 times. The standard deviation of the leaf area almost equals the mean value. The average area of a $S$. dasyclados leaf is approximately three times larger than the average area of a $S$. viminalis leaf, mainly due to the larger width of the former.

For calibration of the leaf area model, we need the mean species-specific value of the leaf form-factor $\bar{K}_{\mathrm{L}}$. The mean value and variation of the form-factor $K_{\mathrm{L}}$, calculated from Eq. (1), are determined by the statistical properties of $l_{1}, l_{2}$, and $S_{\mathrm{L}}$. However, $K_{\mathrm{L}}$ is independent of each individual measured leaf parameter and seems to be a true species-specific parameter. The probability density function $f_{\mathrm{KL}}$, calculated from experimental data, is given in Figs. $3 \mathrm{a}$ and $3 \mathrm{~b}$ for $S$. viminalis and $S$. dasyclados, respectively.

Among commonly used theoretical distribution functions, normal distribution seems to be the best approximation for $f_{\mathrm{KL}}$. For $S$. dasyclados fitting is very good, but the fit is only satisfactory for $S$. viminalis. It is noteworthy that $K_{\mathrm{L}}$ has normal distribution despite the fact that the input parameters $l_{1}, l_{2}$, and $S_{\mathrm{L}}$ have lognormal distribution.

Table 3. Statistical parameters of leaves of Salix viminalis and S. dasyclados. Measurements made during 1996-2001 at Tartu Observatory, Estonia

\begin{tabular}{l|c|c|c|c|c|c}
\hline & Mean value & \multirow{2}{*}{$\begin{array}{c}\text { Standard } \\
\text { deviation }\end{array}$} & \multicolumn{2}{c|}{$\begin{array}{c}\text { Parameters of } \\
\text { lognormal distribution }\end{array}$} & \multirow{2}{*}{ Min } & Max \\
& & \multicolumn{7}{c}{ S. viminalis, $n=2941$} & $\rho$ & \\
\hline Leaf length $l_{1}, \mathrm{~mm}$ & 75.2 & 45.6 & 1.774 & 0.638 & 9 & 232 \\
Max leaf width $l_{2}, \mathrm{~mm}$ & 6.6 & 2.9 & -0.528 & 0.436 & 12 & 19 \\
Leaf area $S_{\mathrm{L}}, \mathrm{mm}^{2}$ & 423 & 465 & 0.877 & 1.017 & 10 & 2684 \\
& \multicolumn{7}{c}{ S. dasyclados, $n=1444$} \\
Leaf length $l_{1}, \mathrm{~mm}$ & 87.0 & 43.9 & 2.041 & 0.491 & 16 & 215 \\
Max leaf width $l_{2}, \mathrm{~mm}$ & 19.1 & 7.3 & 0.587 & 0.349 & 4.5 & 48 \\
Leaf area $S_{\mathrm{L}}, \mathrm{mm}^{2}$ & 1317 & 1290 & 2.211 & 0.837 & 60 & 7000
\end{tabular}


As is evident from Table 2, the lowest value of $K_{\mathrm{L}}$, allowed by Eq. (14), is $9 / 16(\approx 0.55)$. Figures $3 \mathrm{a}$ and $3 \mathrm{~b}$ show that this condition agrees quite well with experimental data.

We calculated also the probability distribution $f_{\beta}$ of the leaf shape parameter $\beta$ using the probability distribution of $K_{\mathrm{L}}$ and Eqs. (13) and (14). These probability density functions $f_{\beta}$ for S. viminalis (Fig. 3c) and S. dasyclados (Fig. 3d) are similar to $f_{\mathrm{KL}}$. As in the case of $K_{\mathrm{L}}$, normal distribution yields better data fitting for $S$. dasyclados than for $S$. viminalis.

Since the form-factors of some of the measured leaves were below the theoretical limit of 9/16 (see Figs. 3a and 3b), it was impossible to calculate shape parameters for these leaves. To obtain the best possible fit, we had to substitute the minimum allowed value of $K_{\mathrm{L}}$ for the real form-factor of these leaves, i.e. their shape parameter was taken to be equal to one, resulting in a peak of the probability density function at $\beta=1$ (see Figs. 3c and 3d). As the normal distribution function was fitted to the data presented in the figure, the quality of the fit is reduced and the distribution maximum is displaced. Although this can be considered a shortcoming of the proposed shape function, form-factors of most leaves fall in


Fig. 3. The probability density histograms of the leaf form-factor $K_{\mathrm{L}}(\mathrm{a}, \mathrm{b})$ and the leaf shape parameter $\beta$ (c, S. viminalis; d, S. dasyclados) fitted by normal distribution. The parameters of distribution are presented in Table 4. 
the appropriate range. To avoid the distortion of the distribution density function, the mean value of $\beta$ and its standard deviation in Table 4 are calculated from mean $K_{\mathrm{L}}$ and its standard deviation assuming linear relationship between $K_{\mathrm{L}}$ and $\beta$. This guarantees that the mean shape factor $\bar{\beta}$ used in modelling and calculations will correspond to species-specific $\beta$. The difference between the form-factors of the two willow species (Table 4) is small but statistically relevant, resulting in different values of $\beta$ and hence in different leaf shapes.

The test data set consisting of one-third of all measurements was used to evaluate the accuracy of the determination of leaf area (and hence $\beta$ ) using Eq. (1) and species-specific form-factors. The correlations shown in Fig. 4 are very good, $R^{2}=0.99$ both for $S$. viminalis and $S$. dasyclados. Figure 4 also illustrates the applicability of species-specific form-factors, as the mean value $\bar{K}_{\mathrm{L}}$ works equally well for large as well as for small leaves.

It is interesting how exactly the shape function $f_{\mathrm{L}}\left(x, \beta, l_{1}, l_{2}\right)$ fits the shape of the real leaf. Figure 5 depicts scanned leaf blades and shape functions $f_{\mathrm{L}}(x)$ calculated from Eq. (7). The leaves were selected to represent different leaf shapes and sizes in the nature. Generally, Eq. (6) describes better large full-grown leaves, smaller leaves tend to have a more intricate shape.

The error of calculating the area of a leaf with the mean form-factor is less than $11.5 \%$ for $S$. dasyclados and less than $18 \%$ for $S$. viminalis at $95 \%$ confidence

Table 4. Species-specific mean values and standard deviations of the leaf form-factor $K_{\mathrm{L}}(\beta)$ and shape parameter $\beta$ for two Salix species

\begin{tabular}{c|c|c|c|c}
\hline & \multicolumn{2}{|c|}{ S. viminalis } & \multicolumn{2}{c}{ S. dasyclados } \\
\cline { 2 - 5 } & Mean & SD & Mean & SD \\
\hline \multirow{2}{*}{$K_{\mathrm{L}}(\beta)$} & 0.691 & 0.057 & 0.661 & 0.041 \\
$\beta$ & 0.650 & 0.153 & 0.732 & 0.111
\end{tabular}
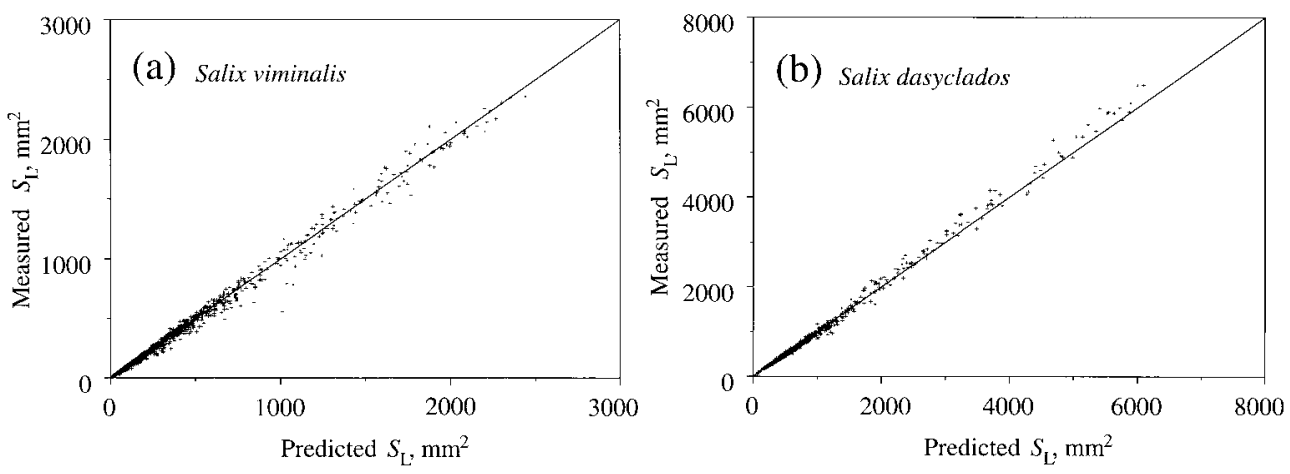

Fig. 4. Leaf areas calculated by Eq. (1) versus measured $S_{\mathrm{L}}$ : a, Salix viminalis, $R^{2}=0.991$; b, $S$. dasyclados, $R^{2}=0.996$. 
(a) Salix viminalis

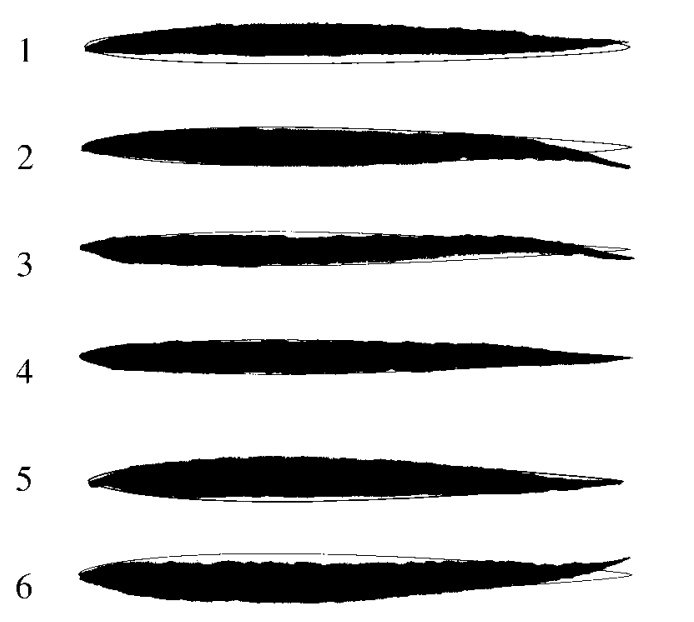

(b) Salix dasyclados

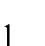

2

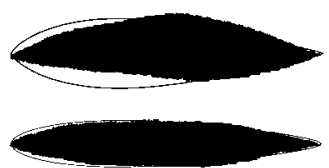

3

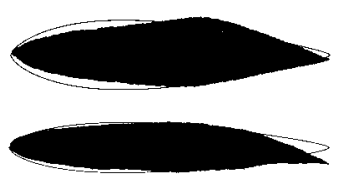

5

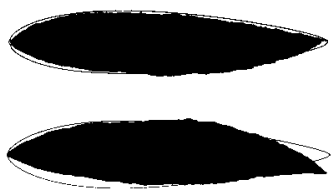

Fig. 5. Scanned leaf blades and leaf shape functions $f_{\mathrm{L}}(x)$ (Eq. (7)) obtained using the real formfactor of the leaf. Leaf dimensions are given in relative units with leaf length normalized to one. $\Delta_{\mathrm{SL}}(x)$ expresses the difference between the scanned leaf area and the area calculated from Eq. (1) using the mean form-factor $\bar{K}_{\mathrm{L}}$.

\begin{tabular}{c|c|c|c|c|c|c}
\hline \multirow{2}{*}{} & \multicolumn{7}{|c}{ Leaf number } \\
\cline { 2 - 7 } & 1 & 2 & 3 & 4 & 5 & 6 \\
\hline
\end{tabular}

\section{$l_{1}, \mathrm{~mm}$}

$l_{2}, \mathrm{~mm}$

$S_{\mathrm{L}}, \mathrm{mm}^{2}$

$K_{\mathrm{L}}$

$\Delta_{\mathrm{SL}}, \%$

141
9
950
0.748
7.6

$l_{1}, \mathrm{~mm}$

72

$l_{2}, \mathrm{~mm}$

$S_{\mathrm{L}}, \mathrm{mm}^{2}$

$K_{\mathrm{L}}$

$\Delta_{\mathrm{SL}}, \%$

16
760
0.656

$-0.7$

169
12
1420
0.698
1

a, Salix viminalis

$\begin{array}{cccc}205 & 216 & 197 & 204 \\ 13 & 14 & 16 & 16 \\ 1770 & 1960 & 2080 & 2290 \\ 0.666 & 0.674 & 0.681 & 0.590 \\ -3.8 & -2.6 & -1.5 & 1.4\end{array}$

b, Salix dasyclados

107
16
1240
0.724
8.8

97
21
1390
0.681
3

122
19
1630
0.703
6.1

$\begin{array}{cc}143 & 145 \\ 28 & 30 \\ 2900 & 3020 \\ 0.725 & 0.695 \\ 9 & 5\end{array}$


level. The precision of fitting $f_{\mathrm{L}}(x)$ to leaf contour is harder to estimate quantitatively, for unbent leaves (midrib is close to a straight line) the difference is negligible; the error is larger for damaged or curved leaves.

The reasonably good agreement between the actual and the modelled leaf contours makes it possible to use this analytical function in models of radiation transfer. Use of analytically calculated leaf borders may reduce computation time and digitization error, compared with the case of leaves described with a large but limited number of points or triangles. Also, the leaf can be provided with a third dimension by adding a curvature to its midrib or by treating the plane on which the leaf is located as a more complex surface.

Three out of the four commonly used leaf shapes in Fig. 1 have fixed shape factors. This makes it impossible to fit measured data to these shapes as well as to compensate for between-species variability. This problem can be addressed by using analytical shape functions; $f_{\mathrm{L}}$ provided by Eq. (7) is smooth and allows for different shape factors in the useful range. Although its first derivative is not determined at endpoints, this does not affect actual leaf shape, as can be seen in Fig. 2d. Another advantage of Eq. (7) is the quasi-linear relationship between $\beta$ and $K_{\mathrm{L}}$, which simplifies the interpretation of changes in $\beta$.

Although Eq. (7) does have a more complex shape than many other functions used to approximate leaf shape, it is compensated by the small number of parameters required to fully describe the modelled leaf. The dependence of the shape function $f_{\mathrm{L}}$ on only three parameters, $l_{1}, l_{2}$, and $\beta$ (or $K_{\mathrm{L}}$ ), makes it more robust compared with triangulation or fitting by polynomials.

Another weakness of the shape function $f_{\mathrm{L}}$ (Eq. (7)) is that the relative location of the maximum width along the midrib, $x_{m} / l_{1}$, varies only in a limited interval of $0.335-0.38$. Our measurements with leaves of $S$. viminalis and $S$. dasyclados show that for real leaves, the interval for $x_{m} / l_{1}$ is considerably larger. However, for long and narrow leaves, the practical determination of $x_{m}$ is quite erroneous, the value of the first derivative of $f_{\mathrm{L}}(x)$ is close to zero in a large interval of $x / l_{1}$ and this does not have an important effect on the goodness of fit of $f_{\mathrm{L}}(x)$ to the actual leaf contour.

For further studies, it is necessary to clarify whether it is possible to determine the shape factor $\beta$ from measurements of $x_{m} / l_{1}$, i.e. whether it is possible to determine the location of $x_{m}$ with reasonable accuracy, and whether analytical leaf shape functions (like the one proposed in this work, given by Eq. (7), or other analytical functions) can describe the variation of $x_{m}$ with reasonable precision. To accomplish this task, other species with long narrow leaves (e.g. cereals, eucalyptus, reed, etc.) should be studied.

\section{ACKNOWLEDGEMENTS}

The research was supported by the ESF grant No. 4699. The authors thank Mrs. Eneken Ross for assistance in field measurements, and Mrs. Viivi Randmets and Mrs. Ester Jaigma in preparing the manuscript. 


\section{REFERENCES}

Andrieu, B., Ivanov, N. \& Boissard, P. 1995. Simulation of light interception from a maize canopy model constructed by stereo plotting. Agric. For. Meteorol., 75, 103-119.

Aries, F., Prevot, L. \& Monestiez, P. 1993. Geometrical canopy modelling in radiation simulation studies. In Crop Structure and Light Microclimate, Characterization and Application (Varlet-Grancher, C., Bonhomme, R. \& Sinoquet, H., eds.), pp. 159-173. Inra Editions, Paris.

Bonhomme, R. \& Varlet-Grancher, C. 1978. Estimation of the gramineous crop geometry by plant profiles including leaf width variations. Photosynthetica, 12, 193-196.

Cescatti, A. 1997. Modelling the radiative transfer in discontinuous canopies of asymmetric crowns. 1. Model structure and algorithms. Ecol. Modell., 101, 263-274.

Chen, J. M. \& Black, T. A. 1992. Defining leaf area index for non-flat leaves. Plant Cell Environ., 15, 421-429.

Chen, S. G., Ceulemans, R. \& Impens, I. 1994. A fractal-based Populus canopy structure model for the calculation of light interception. For. Ecol. Manage., 69, 97-110.

España, M., Baret, F., Chelle, M., Aries, F. \& Andrieu, B. 1998. A dynamic model of maize 3D architecture: an application to the parameterization of the clumpiness of the canopy. Agronomie, 18, 609-627.

España, M., Baret, F., Aries, F., Andrieu, B. \& Chelle, M. 1999. Radiative transfer sensitivity to the accuracy of canopy structure description. Agronomie, 19, 241-254.

Fournier, C. \& Andrieu, B. 1998. A 3D architecture and process-based model of maize development. Ann. Bot. (London), 81, 233-250.

Govaerts, Y. M. 1996. A model of Light Scattering in Three-Dimensional Plant Canopies: A Monte Carlo Ray Tracing Approach. Space Appl. Inst. Joint Res. Centre European Commission, Luxenburg.

Ivanov, N., Boissard, P., Chapron, M. \& Andrieu, B. 1995. Computer stereo plotting for 3-D reconstruction of a maize canopy. Agric. For. Meteorol., 75, 85-102.

Kellomäki, S. \& Oker-Blom, P. 1983. Canopy structure and light climate in a young Scots pine stand. Silva Fenn., 17, 1-21.

Knyazikhin, Y. V., Marshak, A. L. \& Myneni, R. B. 1992. Interaction of photons in a canopy of finite-dimensional leaves. Remote Sens. Environ., 39, 61-74.

Kvet, J. \& Marshall, J. K. 1971. Assessment of leaf area and other assimilating plant surfaces. In Plant Phototsynthetic Production, Manual and Methods (Šestak, Z., Čatsky, J. \& Jarvis, P. G., eds.), pp. 517-555. Dr. W. Junk N. V. Publ., The Hague.

Lewis, P. 1999. Three-dimensional plant modelling for remote sensing simulation studies using the Botanical Plant Modelling System. Agronomie, 19, 185-210.

Moulia, B. \& Sinoquet, H. 1993. Three-dimensional digitizing systems for plant canopy geometrical structures: a review. In Crop Structure and Light Microclimate, Characterization and Application (Varlet-Grancher, C., Bonhomme, R. \& Sinoquet, H., eds.), pp. 183-193. Inra Editions, Paris.

Myneni, R. B., Asrar, G., Kanemasu, T., Lawlor, D. J. \& Impens, I. 1986a. Canopy architecture, irradiance distribution on leaf surfaces and consequent photosynthetic efficiencies in heterogeneous plant canopies. 1. Theoretical considerations. Agric. For. Meteorol., 37, 189-204.

Myneni, R. B., Asrar, G., Wall, G. W., Kanemasu, T. \& Impens, I. 1986b. Canopy architecture, irradiance distribution on leaf surfaces and consequent photosynthetic efficiencies in heterogeneous plant canopies. 2. Results and discussion. Agric. For. Meteorol., 37, 205-218.

Nilson, T. \& Ross, J. 1997. Modeling radiative transfer through forest canopies: implications for canopy photosynthesis and remote sensing. In The Use of Remote Sensing in the Modeling of Forest Productivity (Gholz, H. L., Nakane, K. \& Shimoda, H., eds), pp. 23-60. Kluwer Acad. Publ., Dordrecht. 
Prevot, L. \& Brunet, Y. 1993. Estimating vertical profile of the leaf inclination distribution function: the silhouette method. In Crop Structure and Light Microclimate, Characterization and Application (Varlet-Grancher, C., Bonhomme, R. \& Sinoquet, H., eds.), pp. 195-200. Inra Editions, Paris.

Ross, J. 1981. The Radiation Regime and Architecture of Plant Stands. Dr. W. Junk Publishers, The Hague.

Ross, J. K. \& Marshak, A. L. 1988. Calculation of canopy bidirectional reflectance using the Monte Carlo method. Remote Sens. Environ., 24, 213-225.

Ross, J. \& Ross, V. 1996. Phytometrical characteristics of the willow plantation at Tõravere. In Short Rotation Willow Coppice for Renewable Energy and Improved Environment. Proc. Joint Swedish-Estonian Seminar, Sept 24-26, 1995 (Perttu, K. \& Koppel, A., eds.). Swedish Univ. Agric. Sci. Uppsala, Report 57, 133-145.

Ross, J. \& Ross, V. 1998. Statistical description of the architecture of a fast growing willow coppice. Agric. For. Meteorol., 91, 23-37.

Shabanov, N. V., Knyazikhin, Y., Baret, F. \& Myneni, R. B. 2000. Stochastic modeling of radiation regime in discontinuous vegetation canopies. Remote Sens. Environ., 74, 125-144.

Shibayama, M., Akiyama, T. \& Munakata, K. 1985. A portable field ultrasonic sensor for crop canopy characterization. Remote Sens. Environ., 18, 269-279.

Sinoquet, H. \& Andrieu, B. 1993. The geometrical structure of plant canopies: characterization and direct measurement methods. In Crop Structure and Light Microclimate, Characterization and Application (Varlet-Grancher, C., Bonhomme, R. \& Sinoquet, H., eds.), pp. 131-158. Inra Editions, Paris.

Sinoquet, H. \& Bonhomme, R. 1989. Modélisation de l'interception des rayonnements solaires dans une culture en rangs. II. Structure géométrique du couvert et validation du modéle. Agronomie, 9, 619-628.

Sinoquet, H., Moulia, B. \& Bonhomme, R. 1991. Estimating the three-dimensional geometry of a maize crop as an input of radiation models: comparison between three-dimensional digitizing and plant profiles. Agric. For. Meteorol., 56, 233-249.

Sinoquet, H. \& Rivet, P. 1997. Measurement and visualisation of the architecture of an adult tree based on a three-dimensional digitising device. Trees, 11, 265-270.

Sinoquet, H., Thanisawanyang-Kura, S., Mabrouk, H. \& Kasemsap, P. 1998. Characterization of the light environment in canopies using 3D digitizing and image processing. Ann. Bot., 82, 203-214.

Sinoquet, H., Valmorin, M., Cabo, X. \& Bonhomme, R. 1993. DALI: an automated laser distance system for measuring profiles of vegetation. Agric. For. Meteorol., 67, 43-67.

Stenberg, P., Smolander, H. \& Kellomäki, S. 1993. Description of crown structure for light interception models: angular and spatial distribution of shoots in young Scots pine. Stud. For. Suec., 191, 43-50.

Tanaka, S., Yamaguchi, J. \& Takeda, Y. 1998. Measurement of forest canopy with a laser plane range-finding method - development of a measurement system and applications to real forests. Agric. For. Meteorol., 91, 3-4.

Ustin, S. L., Martens, S. N. \& Vanderbilt, V. C. 1991. Canopy architecture of a walnut orchard. IEEE Trans. Geosci. Remote Sens., 29, 843-851.

Vanderbilt, V. C. 1985. Measuring plant canopy structure. Remote Sens. Environ., 18, 281-294.

Vanderbilt, V. C., Bauer, M. E. \& Silva, L. F. 1979. Prediction of solar irradiance distribution in a wheat canopy using a laser technique. Agric. Meteorol., 20, 147-160.

Vanderbilt, V. C. \& Kilgore, R. W. 1981. Application of computer axial tomography (CAT) to measuring crop canopy geometry. In Int. Geosci. and Remote Sens. Symp. (IGARSS'81), Washington D.C. Digest, Vol. 2, pp. 1162-1167. New York. 


\title{
Kitsaste lihtlehtede kuju ja pindala
}

\author{
Matti Mõttus, Juhan Ross ja Vello Ross
}

Nüüdisaegsetes taimkatte kiirguslevi mudelites kasutatakse üksikasjalikku informatsiooni istanduse ja taime kolmemõõtmelisel kirjeldamisel. Seesuguses mudelis on väikseimaks kirjeldatavaks elemendiks leht (okaspuudel võrse). Taimelehtede kuju ja pindala suure varieeruvuse tõttu on nende modelleerimiseks kasutatud erinevaid meetodeid, siinses töös on esitatud analüütiline kujufunktsioon tasaste kitsaste lehtede kirjeldamiseks. Lehe kujufunktsioon võimaldab arvutada lehe poollaiuse kohal $x$ kolme parameetri - lehe pikkuse, lehe maksimaalse laiuse ja kuju - abil eeldusel, et lehe rood ühtib $x$-teljega.

Mudelit on rakendatud kahe pajuliigi, Salix viminalis'e ja Salix dasyclados'e, lehtede kirjeldamisel. Mõõtmised toimusid aastatel 1996-2001 Tartu Observatooriumis Tõraveres. Lehe pikkuse, maksimaalse laiuse ja pindala statistiline analüüs tõi esile nende parameetrite suure varieeruvuse: Salix viminalis'e lehe pindala on vahemikus $10-2700 \mathrm{~mm}^{2}$, Salix dasyclados' el on see näitaja $6-7000 \mathrm{~mm}^{2}$. Suurest varieeruvusest hoolimata kirjeldab väljapakutud kujufunktsioon lehe pindala ja kuju küllalt täpselt. Salix dasyclados'e lehe kirjeldamisel on täpsus mõnevõrra suurem kui Salix viminalis'e puhul. 